\title{
PODER, ESTADO Y DEMOCRACIA. México y las elecciones del 2006
}

\author{
Rutilo T. Rea B.*
}

RESUMEN

En la vida política, económica e ideológica, el poder es considerado como una relación social que se expresa a través de las estructuras del Estado, el cual puede ser ejercido por la fuerza y la violencia, pero también a través del consenso y los acuerdos. En estas relaciones sociales de poder, se ha puesto de manifiesto que en México se ha ido consolidando una nueva hegemonía en el bloque de poder dominante, encabezado por la clase empresarial, la cual puso a prueba su poder económico, político e ideológico, en el proceso electoral del 2 de julio del 2006. Encontró como aliados a la jerarquía eclesiástica y a los medios masivos de comunicación, que junto al rumor, $y$ a la mistificación que realizan del Estado, diseñaron toda una estrategia mediática de gran envergadura, que permitió el triunfo del candidato del ahora Partido oficial.

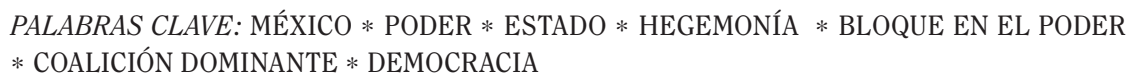

\section{ABSTRACT}

In the political, economical and ideological life, power is considered a social relation that is expressed with state structures, which can be executed by force of violence but also by consensus and agreements. In these social relations of power in Mexico, it is very clear that the dominant block is the one leading by the entrepreneur sector, which placed all their economic, politic an ideological power to the test in country's latest elections in July, 2, 2006. This group joined forces with the clerical group and also with the media, and by means of gossips and mystification of the state, they developed a media strategy that reached the whole country. This allowed the victory of the candidate of the ruling party.

KEY WORDS: MÉXICO * POWER * STATE $*$ ONE LEADING DOMINANT BLOCK * DOMINANT COALITION $*$ DEMOCRACY

\section{RÉSUMÉ}

Dans la vie politique, économique et idéologique, le pouvoir est une relation sociale qui s'exprime à travers les structures de l'Etat, et qui peut étre exercée par la force et la violence, mais aussi à travers le consensus et les accords. Dans ces relations sociales de pouvoir, il s'est mis en place au Mexique une nouvelle hégémonie chez 
le bloque de pouvoir économique, politique et idéologique à l'occasión du processus éléctoral du 2 juillet 2006. Tout en ayant en alléis la hiérarchie éclésiale et les médias, lesquels, avec la rumeur et la mystification qu' ils font de l'etat ont déssiné une stratégie médatique de grosse envergure, rendant possible le triomphe du candidat du Parti officiel

MOTS CHEF: MÉXICO $*$ POUVOIR * ÉTAT $*$ HÉGÉMONIE $*$ BLOQUE AU POUVOIR * COALITION DOMINANTE $*$ DÉMOCRATIE

\section{INTRODUCCIÓN}

En el ejercicio individual, el poder es definido como la fuerza o capacidad para realizar una actividad física o mental. Sin embargo, en la esfera política, económica o ideológica, el poder solo puede manifestarse como una relación social. En efecto, se podría decir precisamente que la esencia fundamental de toda actividad política es su relación con el poder.

Desde los autores clásicos como Aristóteles y Montesquieu, pasando por los análisis de Marx y Lenin, hasta los pensadores de la democracia como Bobbio, Michel y Mosca, han considerado a la política como una relación social de poder, este no necesariamente se manifiesta a través de la fuerza, la imposición o la violencia, también puede mostrarse a través del consenso, el acuerdo o la participación de los diversos actores de la sociedad ${ }^{1}$.

Para que el poder pueda ejercerse bajo una perspectiva u otra, requiere de instrumentos, órganos, aparatos o instituciones que emanan del Estado y permean la estructura del proceso democrático.

El presente trabajo tiene por objeto analizar el papel que se ejerce desde el poder político, económico e ideológico en la configuración del Estado mexicano, destacando por su importancia actual la presencia de una coalición hegemónica encabezada por la clase empresarial ${ }^{2}$, la cual ha

Jaime Osorio habla de una perspectiva vertical y una horizontal en el análisis político (1997: 17).

Por empresario no solo entendemos al dueño de los medios de producción, sino a todos los que ejercen un determinado control del capital. La lista abarca desde presidentes, vicepresidentes, gerentes, accionistas, ejecutivos financieros... que en ocasiones tienen una ideología más conservadora, más ortodoxa y más reaccionaria que los propios dueños del capital. ascendido al poder político desde el triunfo de Vicente Fox. Tomamos como marco de referencia el proceso electoral mexicano vivido recientemente el 2 de julio de 2006.

\section{DEFINIENDO AL ESTADO}

Iniciaremos nuestro análisis tratando de definir al estado y sus complejas interrelaciones con la política, la economía y el sistema ideológico. Asumiendo una perspectiva crítica de las tesis marxistas.

Originalmente, el marxismo partía de la tesis de que el Estado era un instrumento de represión de una clase sobre otra, sobre todo en El Estado y la revolución de Lenin, se estableció este énfasis que perduró durante mucho tiempo en el análisis marxista. Sin embargo, si consideramos que el marxismo no se agota en los límites de lo dicho por Marx, Engels o Lenin, el concepto se enriquecería bajo una perspectiva de análisis dialéctico, donde las categorías no serían perdurables en el tiempo, sino que se modifican o se enriquecen. En este sentido, Gramsci propone un avance al señalar que el Estado no puede mantener su dominación solo a través de la represión, es necesario el consenso y la negociación con las clases que no detentan el poder. En su análisis destaca el concepto de hegemonía, el cual se considera como un sistema ideológico-institucional que influye, $y$ define el quehacer económico, político y cultural del Estado. Dicho autor, supera la visión instrumentalista, pues bajo esta perspectiva, sería imposible que las clases dominadas asumieran el poder. Sin embargo, el Estado tampoco debe ser visto como una institución autónoma e independiente de las contradicciones de clase, o que esté por encima de ellas, pues ni el Estado moderno se estructura - como señala Uvalle - solo tomando en cuen- 
ta lo que es y desea la sociedad, o bien, como un poder que no sea adverso a ella (véase Uvalle, 1999), pues ello haría suponer la existencia de un estado con autonomía absoluta, y en el que la sociedad resultaría homogénea, sin contradicciones, pugnas, manipulaciones, exclusiones 0 marginaciones. En realidad el Estado se mueve en el ámbito de la razón y la fuerza, de la represión y el consenso, entre el bien común y el interés parcial, entre la sociedad civil y la clase política. Aunque tiene como uno de sus propósitos fundamentales el bienestar de los que detentan el poder, se mistifica como razón y reino del bien común y del interés general. Como señala Poulantzas, debe ser visto como una condensación material de una relación de fuerzas entre clases y fracciones de clase, dentro del cual se estructura y define no solo las relaciones sociales de producción, sino también las de carácter ideológico y las del dominio político (1978: 153). No debe considerarse que el control del estado es una pirámide en donde aquel que ocupe el vértice asegura su control, pues no es un bloque monolítico, sino un campo estratégico en el que se manifiestan las contradicciones, son precisamente estas las que constituyen el Estado, están presentes en su armazón material y estructuran así su organización (Ibid: 159).

Por lo tanto, no debe confundirse estado con aparatos de estado ${ }^{3}$, pues este siempre posee una autonomía relativa con respecto a tal o cual fracción del bloque en el poder ${ }^{4}$; $y$ los aparatos son instancias mediadoras que sirven de contacto y representación entre el poder de Estado y las distintas clases $y$ fracciones de clase, o la llamada sociedad civil.

Bajo esta perspectiva, el Estado entonces no debe ser concebido solo como instrumento

3 Althusser hablaba de aparatos represivos (policía, ejército, paramilitares...) que actúan fundamentalmente a través de la fuerza física; $y$ aparatos ideológicos (medios de comunicación, familia, escuela...) que actúan principalmente a través de la dominación ideológica. Aquí entendemos a los aparatos ideológicos y represivos como la instancia mediadora entre el poder del Estado y la sociedad.

Coalición dominante al interior del Estado y que impone su hegemonía al conjunto de la sociedad. de represión, en el cual se puede disponer de él a voluntad y libre albedrío de las clases dominantes (Crítica al Estado-Cosa), pero tampoco como una institución por encima o al margen de las luchas sociales, económicas o políticas, pues no es neutral a ellas, ni mantiene una autonomía absoluta (Crítica al Estado-Sujeto) ${ }^{5}$. El Estado es una condensación material de una relación de fuerzas, un campo y un proceso estratégico donde se entrelazan nudos y redes de poder, que se articulan y presentan a la vez contradicciones y desfases entre sí.

Las luchas no solo se presentan entre las fracciones y las clases dominantes, también se extienden a las clases dominadas.

Las clases dominantes, a través de su hegemonía ${ }^{6}$, establecen juegos y compromisos provisionales entre el bloque en el poder $y$ las clases dominadas. Es a través de la autonomía relativa del Estado como se organizan en el poder. Pero el papel del Estado respecto a las clases dominadas no es desde fuera, ya que el estado no solo condensa la relación de fuerzas entre la fracción dominante, sino también entre este y las clases dominadas, las cuales lo hacen como fuentes opositoras o de resistencia, no con un poder real propio.

Los aparatos de Estado organizan y unifican el bloque en el poder por un lado, $y$ desorganizan y dividen a las clases dominadas por otro, polarizándolas, confrontándolas y disminuyendo el peso de sus organizaciones políticas propias.

No es que consideremos que el Estado lo sea todo ${ }^{7}$. Indudablemente que existen relaciones de poder o dominación (familiares, interpersonales o sociales) que escapan a los quehaceres fundamentales de este órgano de dirección; pero aquí nos referimos a las relaciones políticas,

5 Véase Nicos Poulantzas op cit: 158.

6 Una fracción o clases es hegemónica cuando aparece como la representante ideológica y política de toda la sociedad y puede dictar la orientación fundamental del Estado.

7 En los regímenes fascistas o socialistas, el Estado se considera con poder absoluto, fuera de él es oponerse o al nacionalismo o a la revolución, según el caso, pero esto es lo que los convierte en estados totalitarios. 
económicas e ideológicas, en los que directa o indirectamente el Estado interviene en todo este tipo de manifestaciones $y$ no lo hace de manera neutral.

\section{ESTADO, PODER POLÍTICO Y DEMOCRACIA}

Si consideramos que la política no se manifiesta en abstracto sino como una lucha constante por mantener o conquistar el poder, entonces no está exenta de conflictos y confrontaciones que en ocasiones llega a la violencia. Sin embargo también implica establecer alianzas, acuerdos o negociaciones entre los diversos grupos sociales. Pero como Norberto Bobbio señala: "el poder pertenece de manera inexorable a las elites (por lo que resulta ser) una teoría realista de la política" (Medina, 1998:16). Para poder perpetuarse como Estado debe "ser agente afectivo, aunque parcial, del interés general. De no ocurrir esto último, el aparato de dominación resultaría débil" (Meyer, 1998: 32). En efecto, el Estado se mistifica y se retrata como sirviendo al conjunto de la sociedad, ocultando sus antagonismos de clase a través de la legalidad jurídica $y$ la legitimidad social, (presencia de ciudadanos en los órganos electorales, el estado de derecho, el respeto institucional, etc.).

En estas mistificaciones, muchas veces no se asume el poder real por parte de los trabajadores. Es más, la fracción dominante puede permutar órganos en descenso por aparatos de mayor importancia en un periodo determinado. Es decir, puede cambiar espacios o terrenos de poder real por campos de poder formal, incluyendo la presidencia. "Aparatos que antes eran decorativos o de un papel secundario, comienzan a desempeñar un papel decisivo: tribunales, congresos, magistraturas, etc." (Poulantzas, op. cit.: 152).

En este sentido, la democracia del pueblo, para el pueblo y por el pueblo, continúa siendo una utopía. Esto no significa sin embargo, que en el "mundo posmoderno" no se hayan dado avances democráticos y mayor participación de los ciudadanos, lo que implica un cambio sustancial sobre los regímenes totalitarios, fascistas o autoritarios, pero aun con todos estos avances, la democracia sigue siendo una relación de poder.
Veamos:

$\diamond$ En un régimen democrático, la regla principal es la de las mayorías, y las decisiones colectivas son obligatorias para todos.

$\diamond$ Se privilegia el papel de las elecciones y la actividad ciudadana, quienes tienen la tarea de pensar y construir el "buen gobierno" y el "bien común" si obtienen la mayoría de los votos y se garantiza el estado de derecho, incluyendo la protección de las minorías.

$\diamond$ La soberanía del pueblo se "legitima" a través de autoridades, cuyo representante es el parlamento o los tribunales electorales, que permite la división de poderes.

$\diamond$ Se supone que los valores de la democracia son: la igualdad, la libertad, la justicia, la tolerancia, la fraternidad $y$ la no violencia.

En fin

... (la) lógica de la democracia insiste en la participación y la igualdad, en la dialéctica de la pluralidad, así como en la formación de acuerdos consensuales para definir las orientaciones de la sociedad, resolver controversias de puntos de vista e intereses, o proteger las soberanías nacionales (Ibarra, 2000:22).

Las críticas que se han realizado a la democracia es que 1) en ella existe un apetito natural por el poder de los líderes, $y$ una vez que este se alcanza no se está dispuesto a renunciar a él. 2) El deseo de dominar existe en todo ser humano y más en aquellos que han obtenido beneficios económicos o políticos en el pasado, 3 ) por lo que la distribución del poder se concentra $y$ reivindican intereses de fracciones.

La llamada transición democrática o la alternancia, no implican el cambio de una clase social a otra, por lo que las masas, el pueblo, no asumen realmente el poder.

¿Qué papel juegan en todo esto los empresarios? ¿Cuáles son sus relaciones con la clase politica? ¿De que manera inciden en la vida democrática, ideológica y económica de la sociedad mexicana? 
EL ASCENSO DE LOS EMPRESARIOS

Y NUEVA HEGEMONÍA EN EL PODER EN MEXICO ${ }^{8}$

Durante muchos años, México vivió bajo la tutela de un presidencialismo y un autoritarismo manifestado en la falta de competencia entre los poderes legislativo, ejecutivo y judicial, lo que le daba un carácter unipersonal y uni-potente a las relaciones de poder. De hecho era en torno al ejecutivo que gravitaban los demás actores sociales: sindicatos, campesinos, intelectuales y empresarios. Fue en el periodo del general Lázaro Cárdenas cuando se transita parcialmente de esta esfera unipersonal a la presencia de las instituciones, las cuales fueron fortaleciendo al Estado Mexicano pero sin dañar la persistencia de los grupos de poder establecidos, mejor conocido como la gran "familia revolucionaria". El movimiento obrero, campesino y popular fue corporativizado a un Estado que impulsó y consolidó el proceso modernizador, incluyendo a los empresarios, a los que se les invitó a trabajar y a crear sus propias organizaciones pero bajos las reglas de la estructuración de un Estado como motor del desarrollo económico, político y social.

Los orígenes de la crisis estructural generada por los gobiernos populistas marcaron un punto de quiebre y confrontación entre la clase política tradicional y los empresarios. "Aquellos acuerdos de la familia revolucionaria iniciados en 1928-29 con el general Calles, llegan a su límite, $y$ los síntomas de agotamiento del régimen autoritario, marca la transición del poder real de los políticos a los tecnócratas (Piñón y Rea; 2000: 25)”.

En efecto, los empresarios que no creían en los beneficios de la Revolución, se organizaron en el Consejo Coordinador Empresarial (CCE) para impugnar las políticas del estado y reducir el papel de las elites populistas. Fue en esta época cuando se unificaron como nunca antes en contra de los programas redistributivos y reformas fiscales, reduciendo sus tasas de inversión, provocando fugas de capital para desestabilizar económicamente al país, organizando paros patronales, financiando campañas publicitarias $y$

8 Para mayor detalle histórico de la consolidación de la clase empresarial como hegemónica en el bloque en el poder, véase a Piñón y Rea; 2000: 19-28. desatando rumores de una intervención militar. De esa manera se va consolidando su posición como grupo hegemónico a través del Partido Acción Nacional (PAN).

La derecha social arriba al gobierno y presiona para el establecimiento de políticas económicas de corte neoliberal, todo ello alimentado por las fuerzas más beligerantes del sector empresarial, quienes ya no se conforman con opinar, sino que deciden dirigir el país, no solo económicamente, sino también en la política. Acción que concluye en su primera etapa, con el triunfo electoral del 2000 de Vicente Fox.

Sin desmeritar el logro del nuevo Presidente de haber sacado de Los Pinos a un partido que tenía congeladas las salidas de la democracia, $y$ la falta de libertad de expresión, consideramos que en la vida política, no se ha dado una transformación sustancial en las relaciones de poder, sino que se limita a una alternancia en la que el Estado mantiene intactas sus estructuras y sigue desempeñando su papel de clase, incluso ahora de manera más nítida.

\section{DEMOCRACIA Y ELECCIONES}

Las elecciones son por antonomasia el elemento fundamental para "consensuar" la democracia. Por desgracia en México se han convertido en un espectáculo mercadotécnico de campañas publicitarias, en los que el debate de las ideas y propuestas de los actores políticos, es sustituido por el descrédito, la guerra sucia, la mentira y la calumnia; $y$ lo que antes era considerado como una lucha por la justicia, la libertad y la igualdad social, hoy se convierte en un verdadero negocio de unos cuantos, $y$ en consecuencia, en un gran derroche del erario público para promocionar el voto. A ello habría que agregar el uso indiscriminado de las encuestas de opinión y la propaganda masiva en los medios de comunicación, que más que brindar información al elector, le genera confusión y desánimo, poniendo de manifiesto que las bases de los partidos políticos, no tienen una opinión que vaya mas allá del voto interno, quedando al servicio de las decisiones de sus líderes o candidatos.

Los órganos de poder real en México, podríamos decir que en la actualidad se encuentran 
en las instituciones electorales como el Instituto Federal Electoral (IFE) y el Tribunal Electoral del Poder Judicial de la Federación (TEPJF), en el poder mediático y religioso, los cuales desempeñaron un papel decisivo en el reciente proceso electoral del 2006.

Lo ocurrido en dicha jornada electoral, ha dejado más dudas que certezas para un organismo como el IFE. No se trata de cuestionar a los representantes electorales ${ }^{9}$ honestos y respetuosos de la ley, pero toda la serie de inexactitudes, errores aritméticos, algoritmos cibernéticos, errores en las actas o mala contabilidad, cómputo de resultados preliminares amañados, boletas encontradas en basureros, una negativa de abrir paquetes para dar transparencia, etc. dejan mucho que desear de una institución que se jacta de absoluta imparcialidad, transparencia y plena confiabilidad, $y$ de que en México, todavía nos queda mucho camino que recorrer en el proceso democrático ${ }^{10}$.

Bajo esta perspectiva, consideramos que los organismos electorales en México, actualmente no representan el poder real del pueblo. Si han significado un avance democrático y un elemento de transición y participación ciudadana, pero para nada significa que se establezcan las decisiones sustanciales de las grandes mayorías.

\section{IDEOLOGÍA Y PODER MEDIÁTICO}

La ideología se establece como el conjunto de ideas y representaciones mentales que se hacen de la realidad o del entorno en el que se vive. Es una visión que puede manifestarse en forma simple o "sentido común" o de manera

En México, la participación de ciudadanos representantes del IFE es importante, pero ello no significa que sean los que toman las decisiones fundamentales de este órgano electoral.

10 El Tribunal Electoral (TEPJF) decidió, no recontar la totalidad de las casillas, como era la demanda de la Coalición por el bien de todos que postulaba a Andrés Manuel López Obrador como candidato a la presidencia, y dejó para siempre la duda de un fraude, pese a que finalmente dio el triunfo a Felipe Calderón candidato del derechista partido oficial (PAN). más elaborada y con un alto nivel de abstracción, pero que implica a su vez, prácticas materiales que se extienden a los hábitos, costumbres y modos de vida.

La ideología organiza la acción y mueve a los sujetos a actuar, moldeando así el conjunto de las prácticas sociales, incluidas las prácticas políticas y económicas.

Según Gramsci, es en el terreno de la ideología donde el hombre adquiere conciencia de su situación y de los conflictos de la estructura, y considera que junto al desarrollo económico hay un desarrollo paralelo de lo ideológico, lo cultural, lo jurídico, religioso, etc. (Saldívar; 1990: 46).

La ideología entonces, no debe verse como un reflejo mecánico de la realidad económica, puede estar condicionada por las fuerzas productivas y las relaciones de producción, pero las prácticas ideológicas tienen autonomía de las prácticas económicas, ya que no se pueden explicar todos los fenómenos a partir de la realidad económica, sería una visión errónea y sumamente reduccionista en el análisis científico, pero como sostiene Poulantzas "la ideología no es algo neutro en la sociedad, solo hay ideologías de clase. La ideología dominante, en particular, consiste en un poder esencial de la clase dominante" (op. cit.: 27). Lo anterior no significa que todas las creencias o "subjetividades" que el ser humano desarrolla en la práctica, tenga que ver con actividades clasistas, más sin embargo, en el devenir histórico de las luchas políticas y económicas no puede ser de otra manera. La naturaleza institucional de las prácticas ideológicas, así como su elaboración y difusión, está conformada por los aparatos ideológicos (escuela, familia, iglesia, partidos, medios de comunicación...). Es a través de estas instituciones "privadas" de la sociedad como se puede - y en realidad se hace - conformar la ideología de la clase dominante, a través de la cual se va ejerciendo la hegemonía económica y política sobre toda la sociedad. "Así, la ideología dominante se encarna en los aparatos de estado que desempeñan el papel de elaborar, inculcar y reproducir esa ideología" (Ibíd: 27). De hecho, la ideología dominante interviene directa o indirectamente en la organización de los aparatos ideológicos y difunde, crea, propaga todo un sistema de valores $y$ creencias, que de una u otra forma contribuyen 
a sostener la legitimidad del orden establecido $y$ los intereses de la clase dominante, $y$ a medida que se internaliza en las grandes masas, estas la hacen propia ("conciencia falsa, alienada") y se genera "el sentido común". Por lo que en periodos de crisis o tensión, las ideologías orgánicas (dominantes) logran los apoyos necesarios, e incluso condicionan $y$ construyen una determinada visión y percepción de la realidad acorde a sus intereses económicos y políticos. Lo anterior, son elementos adicionales del porque un Estado no solo se reproduce a través de la violencia. Los aparatos ideológicos, sobre todo la televisión, además de prohibir, imponer, excluir, engañar, mentir, ocultar y esconder lo que en un momento determinado le es adverso a la clase gobernante, actúan también de manera "positiva", pues crea, transforma y produce realidades que implican avances o triunfos de las clases subalternas o dominadas, pero estas concesiones o conquistas parciales de "las masas populares", no implican cambios radicales en la vida política o económica de un país. La ideología dominante incluso recoge elementos $y$ aspiraciones de las clases que no detentan el poder, $y$ las presenta como preocupaciones propias, pero más que como libertadoras, lo hace con fines de control y manipulación, ya que se inculcan valores predominantes, haciendo que la gente se convenza de la necesidad del orden establecido, hasta llegar a creer $-y$ aceptar - que la desigualdad social y económica es un fenómeno natural y universal. La función de la ideología dominante, es hacer que el trabajador internalice y que haga suyos los valores culturales que legitiman un determinado tipo de relaciones y acepte, sin cuestionarlos, a partir de la difusión amplia y articulada de un sistema de ideas y pensamientos, que derivan en el discurso político de las elites (políticas o económicas) a través de los medios masivos de comunicación.

Este discurso empresarial o "estatal" conforma en lo medular, la ideología orgánica y justificada existencia de un proyecto de desarrollo histórico y cultural de la clase en el poder.

\section{PODER MEDIÁTICO Y ELECCIONES EN MÉXICO}

En México, como ya se señaló, con el triunfo de Vicente Fox, se puso de manifiesto el poder empresarial en el seno del Estado mexicano, pero también sacó a la luz pública, intereses ideológicos ultra conservadores y fundamentalistas de organizaciones como el grupo próvida ${ }^{11}$ y la ya no tan secreta Organización Nacional del Yunque $^{12}$. También han salido a flote los intereses de la Iglesia que cuenta con una presencia nada desdeñable en la estructuración, definición $y$ difusión de la ideología gobernante. Convirtiéndose, junto con los medios electrónicos de difusión, en uno de los aparatos ideológicos de mayor importancia en México ${ }^{13}$ penetrando profundamente en las entrañas del estado laico (?) mexicano. Inclusive, instituciones como Los Legionarios de Cristo cuentan hoy con una institución bancaria: Banco Compartamos.

Toda esta red de intereses ideológicos, políticos, económicos y religiosos, se entretejieron para diseñar una estrategia de campaña a favor del Partido Acción Nacional (PAN) y juntos con la televisión, este poder mediático articuló su maquinaria que se hizo evidente en el proceso electoral del 2 de julio. Las cúpulas empresariales, la jerarquía eclesiástica y los organismos "privados" de carácter "social", desataron una campaña de miedo $y$ de odio que no solo se difundió a través de los spot televisivos, sino también a través del rumor, el "imaginario colectivo" o "el sentido común", influyendo en un importantísimo sector de la población nacional.

Es sabido que los aparatos ideológicos no tienen una capacidad persuasiva que se asuma de manera automática o inmediata, inclusive, puede haber posiciones contrarias a lo que se difunde, pero sí existe en ellos un alto margen de

Organización "privada" con carácter "social" que entre sus objetivos principales está el derecho a la vida $y$ no al aborto, llegando a extremos de forzar a las mujeres a tener a sus hijos después de una violación.

Organismo político clandestino de extrema derecha que ha penetrado en las altas esferas del poder político del gobierno foxista (Delgado, 2003).

13 México se ha caracterizado por ser una sociedad eminentemente católica, pero hasta antes del gobierno de Fox, se había mantenido - al menos en teoría - al margen de las actividades político electorales y respetuosa de las instituciones. 
eficacia comprobada para crear o cambiar formas de pensar y actuar en países como el nuestro, de lo contrario no se pudiera explicar, como los empresarios invirtieron tantos millones para financiar la campaña del candidato del PAN. La lista no se limita a las empresas denunciadas por la Coalición por el Bien de Todos, Rogelio Rebolledo de Pepsico y Eugenio y Federico López Rodea, presidente y vicepresidente de Jumex, sino que también participaron de manera directa o indirecta: Servitje Sendra de Bimbo; Luis Téllez, actual representante de Carlyle; Willam Karma Kassaki, presidente del grupo Hidrosina; Gastón Azcárraga, presidente del grupo Posadas; José Antonio Fernández Carvajar, Presidente de CocaCola Femsa, consejero del grupo Bimbo, Cydsa y el grupo financiero Bilbao-Viscaya, Argentaria Bancomer; Dionisio Garza Medina, presidente del grupo Alfa. Cabe mencionar también a los representantes de Citygroup Banamex, Scotiabank Inverlat, Procter and Gamble, Kimberly Clark, General Electric, Bacardi, Mc. Donalds, Jhonson and Jhonson, Bic, Sara Lee, Microsoft, American Express, entre otras (Véase Carlos Vega; La Jornada, 2006: Sección México SA-Internet).

La intervención empresarial no se limitó al financiamiento. Los grandes industriales y comerciantes, así como banqueros y "productores" de servicios, agrupados en el CCE, utilizaron cartas e historietas promocionando el voto a favor del candidato del PAN y en contra del candidato del Partido de la Revolución Democrática (PRD). Incluso llegaron a realizar reuniones en sus residencias donde "orientaban" el voto "a favor de la continuidad y la estabilidad económica" y en contra de "los cambios bruscos y del populismo".

Precisamente el slogan "un peligro para México" impactó sobre la mente de muchos mexicanos, que sumado al rumor de que "iban a perder sus casas o negocios" o "tener un gobierno similar al de Cuba", cambiaron su voto el 2 de julio.

Todo lo anterior se dio ante los ojos del IFE sin que hiciera nada, aún cuando la ley prohíbe la participación empresarial en los asuntos electorales de México. Las instituciones religiosas también desarrollaron una fervorosa labor a favor del candidato panista, sin que tampoco se dieran impedimentos legales.
El poder mediático no se ha limitado al 2 de julio. Ante un cuestionado proceso electoral, tropelías cometidas antes y después de la jornada, un "triunfo" que todavía es considerado por muchos como ilegítimo, etc., los aparatos ideológicos difunden ahora "el respeto a las instituciones" por ser un "patrimonio público que nadie debe lesionar". El IFE, pareciera que gasta ahora en spot más que en el proceso mismo de las elecciones para legitimarse y para argumentar "un proceso limpio y transparente", en el que participamos "todos los mexicanos". Paradójicamente también el partido político que difundió toda una guerra de odio, miedo y calumnias, ahora llama a "la unidad" y a "conjuntar esfuerzos para crear un México con armonía". La televisión, permanentemente difunde la "terca" actividad de resistencia civil del Partido de la Revolución Democrática; periodistas como Pedro Ferriz de Con, Ruiz Healy, el propio Víctor Trujillo, mejor conocido como el payaso Broso, los comentaristas de radio-fórmula financiera, por mencionar sólo algunos, no esconden su fobia al candidato perredista Andrés Manuel López Obrador (AMLO), llamándolo "demagogo", "naco", "autoritario", "terco", "loco", "violento", "ignorante" $y$ más calificativos que se pudieran imaginar; $y$ más que difundir una información veraz y objetiva, dichos reporteros, se han dedicado a verter opiniones cargadas de desprestigios y mofa del excandidato de la Coalición por el Bien de Todos. La verdad es que los atropellos a la incipiente democracia mexicana, no vienen de AMLO, sino del partido en el poder, la jerarquía eclesiástica y la cúpula empresarial que unieron sus esfuerzos a través del poder mediático, provocando la reacción de un gran movimiento de resistencia civil ciudadana que comienza a rebasar al PRD, pues a la demanda del voto por voto, $y$ ahora la llamada Convención Democrática Nacional, se han sumado intelectuales, artistas, investigadores nacionales y extranjeros, comunidades eclesiales de base e incluso, algunos Consejeros Ciudadanos que participaron en las elecciones del 2006.

Indudablemente que también el candidato del PRD cometió una serie de errores que le restaron popularidad en los medios de información, entre los que destacan: su actitud soberbia y mesiánica; el sentirse confiado e indestructible, en el que con solo su presencia en el gobierno, 
transformaría al país; el considerar complot todo lo que se señalaba en su contra, pero sobre todo el "cállese chachalaca", en alusión a la constante intromisión del Presidente Fox en el proceso electoral, fueron elementos que todas las fuerzas en su contra utilizaron y magnificaron para presentarlo como una persona violenta e insultante, $y$ frenar a toda costa su arribo al gobierno. De hecho, la resistencia civil generada por el conflicto postelectoral ha sido catalogada como "mera terquedad" de un individuo, cuando en realidad se trata de todo un movimiento de masas.

Por desgracia, "el sentido común" olvida —o se le oculta— que Fox, se burló del Presidente Salinas De Gortari; que el PAN fue el principal promotor de la resistencia civil, que implicó el cierre de aeropuertos y carreteras, incendios de alcaldías, bloqueo en vías férreas, boicots a negocios y medios de comunicación, ocupación de puentes internacionales y un apoyo eclesiástico, donde los obispos suspendían misas como protesta ante las "violaciones a la voluntad popular". Esa parte de la población no quiso ver la realidad de un complot orquestado desde la cúpula empresarial, La Suprema Corte de Justicia, el Centro de Investigación y Seguridad Nacional, de empresarios que no pudieron sacar beneficios del gobierno del Distrito Federal que se toparon con un jefe de gobierno, que no les brindó concesiones ni cobijó a sus corruptelas, $y$ al que se sumaron diputados y senadores no solo del PAN, sino también del Partido Revolucionario Institucional (PRI). Fueron estos actores los que trabajaron juntos para promocionar primero los vídeo escándalos y después el desafuero de AMLO; y cuando ello no les rindió frutos, fomentaron junto con la iglesia y los medios electrónicos de comunicación la campaña de "es un peligro para México" que constantemente repetía el candidato del PAN, pues había que impedir a toda $\operatorname{costa}^{14}$ que AMLO llegara a la silla presidencial.

El Tribunal Electoral (TEPJF), al dar el triunfo a Felipe Calderón por desgracia está transmitiendo un mensaje ominoso como señala Armando Bartra: "En México la izquierda no puede

14 El ex canciller Jorge Castañeda hizo el comentario que había que "detener vivo o muerto a López Obrador" (Jornada , agosto del 2006-Internet). llegar al poder por la vía electoral, no por falta de votos, sino porque no se lo van a permitir, con dos saldos mayores: crecimiento del abstencionismo y fortalecimiento de la oposición contra institucional (Jornada, 5 de agosto de 2006).

\section{ESTADO Y ECONOMÍA}

Desde el punto de vista del análisis teórico, resulta complejo "separar" el análisis de una situación concreta. Metodológicamente el Estado puede estudiarse a través de tres campos principales: el político, el económico y el social. La ideología se manifiesta en los tres planos, $y$ los intereses del poder se presentan en ocasiones de manera visible y en otras, mistificándose u ocultando su verdadero carácter de clase.

El ámbito de lo social tiene como columna vertebral de análisis, las luchas que se enraizan en la sociedad civil, y dan vida a lo público (política pública, gestión pública, acciones colectivas,...). Es aquí donde más injerencia, participación y un relativo poder de decisión tienen las clases subalternas ${ }^{15}$, sin que ello implique que dirigen o tengan el poder real del Estado ${ }^{16}$.

En México, durante muchos años se habló de una economía mixta, en la que participaba el Estado, la iniciativa privada y el sector social. La reforma Agraria, el Seguro Social, el INFONAVIT (Instituto de Fomento Nacional a la Vivienda de los Trabajadores), la Educación Pública, las conquistas sindicales expresadas en los contratos colectivos de trabajo, etc. fueron conquistas parciales de las clases dominadas y que hoy viven un extraordinario revés.

El capitalismo puede tolerar la democracia, y como señalábamos, la coalición hegemónica puede ceder espacios de poder formal a cambio de espacios del poder real, incluyendo la Presidencia de la República, pues la política democrática (sufragio universal, derechos

Esto ha hecho pensar en la tesis del que "el Estado somos todos".

$16 \quad$ El ámbito de lo social debe desarrollarse en otro análisis con mayor detalle. El presente artículo se limita a su mención. 
institucionales...) no afectan en esencia el poder económico, ni el sistema de explotación. Es más, la noción de democracia se ha vuelto muy útil como herramienta ideológica en manos de las clases dominantes. Hoy en día, "todos somos democráticos", incluyendo el gobierno represivo de Israel, o el Chile de Pinochet.

La democracia capitalista trata de disentir la actividad política de la económica. Es verdad que con la democracia se generan "protecciones" a las libertades civiles, vigilancia más severa a la arbitrariedad de los estados, una rendición de cuentas a la voluntad popular, etc. pero se deja intacto el dominio de la clase dominante sobre el capital. En este sentido, la economía tiene su propio sistema de compulsión y coerción, sus propias formas de dominación.

En países como México, pese a los avances democráticos y la "alternancia" en el poder, se continúa con las mismas políticas económicas de los gobiernos neoliberales, implicando mayor desempleo, agudización de la pobreza, informalidad en la producción y el comercio, y una migración mayor a los Estado Unidos entre otras.

Contrario a lo que se sostiene, la desregulación económica del Estado, no implica su desaparición o extinción, ni siquiera que ya no participa en las decisiones económicas fundamentales. Más bien sostendríamos que ahora el Estado se pone al servicio del mercado, $y$ se trata de desmantelar ciertas funciones públicas y sociales que antes tenía. De hecho, la política del gobierno foxista es eficientar al Estado incorporando criterios y prácticas empresariales, subordinando el interés público al criterio de rentabilidad empresarial, volviéndose así en un regulador de la actuación de las empresas, no de las contradicciones de la sociedad en su conjunto, $y$ haciendo más nítido el interés de clase y el poder económico ejercido por una coalición hegemónica dominante. Proyecto que sin duda alguna continuara con el ahora declarado Presidente Felipe Calderón del Partido Acción Nacional.

Bajo esta perspectiva de análisis de lo privado (interés, capital, iniciativa privada, ganancia, utilidad, beneficio...) tendrán $-y$ tienen ya- el privilegio de marcar dominantemente el camino para el "crecimiento económico" de México, pues aunque no esté comprobado que el status de propiedad sea el motor del crecimiento y desarro- llo, se pone en él toda la confianza, incluyendo el servicio del estado, ya que este le compra, le ofrece subsidios, exenciones fiscales $y$ hasta beneficios impositivos ${ }^{17}$.

Otro elemento importante del actual capitalismo mexicano, es el número cada vez mayor de grandes empresas de carácter trasnacional. De hecho Eduardo Margáin sostiene que "una nueva coalición conformada por grandes empresas mexicanas, funcionarios tecnócratas y poderosas corporaciones multinacionales incrementaron su poder desde la crisis de liquidez (1982-87) y se apoderaron del gobierno apoyando una nueva política económica (1995: 248)". En efecto, grandes corporaciones económicas tienen una importancia fundamental en el creciente dominio de sectores claves en la vida industrial, financiera y comercial en nuestro país. Por ejemplo, exceptuando el Banco del Norte (Banorte), los demás órganos financieros son de extranjeros, o de socios mayoritarios de procedencia extranjera. En el comercio, empresas como Gigante, Soriana y Comercial Mexicana, han tenido la fuerte competencia del gran corporativo Wall Mart, pues ni juntas, lograrían superarla. Lo anterior no significa que todas las pequeñas y medianas empresas hayan desaparecido, aunque si han cerrado ya muchas de ellas, $y$ otras persisten o se niegan a desaparecer, pero les resulta cada vez más difícil permanecer en el mercado.

En este juego de presiones externas y demandas internas se va configurando la política económica, en la que actúan elites tecnócratas y empresariales. En México, su eficacia está siempre mediatizada por el poder de la fracción —más bien coalición- dominante, en la que los trabajadores, amas de casa, obreros, campesinos, estudiantes y demás grupos de interés local, no están en forma directa en el proceso de las reformas, más bien, se les filtran de una u otra manera, las orientaciones ideológicas y cálculos políticos hegemónicos, que son en definitiva quienes sancionan y autorizan la continuidad o cambio en las

El caso del "cuñado incómodo" Hildelbrando, tal vez sea solo un iceberg de toda una cadena de beneficios que reciben las más poderosas empresas del país, pero seguramente son mucho más las que no pagan impuestos, o lo hacen en proporción menor a la correspondiente. 
políticas económicas. Lo anterior no quiere decir que no existan restricciones, reglas del juego político, alineamientos sociales, circunstancias históricas, un poder — aunque sea formal- más competido, negociaciones con los organismos financieros y acreedores externos, presión de los grupos dominados, etc. pero es en el campo económico, en el que no se ha cedido ni un ápice, ni siquiera en la democracia formal, y donde más nítidamente se ve el interés de clase en función de la propiedad y el control de los medios de producción, es decir, el poder económico.

\section{CONCLUSIONES}

En el análisis social, el poder no puede estudiarse en abstracto, sino como una relación social, en la que los seres humanos entretejen sus deseos, demandas, dominios o presiones en el terreno de la política, la cultura (ideología) o la economía. Las luchas, imposiciones, avances democráticos, acuerdos políticos, etc. se ponen de manifiesto a través de la estructura del Estado, por lo que "una teoría del Estado, es también una teoría de la sociedad y de la distribución del poder en esa sociedad" (Miliband, 1970: 4).

En los últimos años, la mayor parte de los países se han cobijado en el argumento de la democracia, $y$ todos sus avances (sufragio universal, elecciones libres y regulares, libertad de expresión...) han hecho creer que el Estado es un ente neutro, por encima de las contradicciones de clase, cuyo objetivo es regular las diferencias entre los agentes de la sociedad y buscar el bien común. En realidad esta es la forma en que se mistifica y se presenta ante la sociedad, haciendo creer que todos los grupos activos y legítimos de la población pueden hacerse oír en los momentos de decisión. Pero aunque el Estado no es solo instrumento de represión, pues en él confluyen luchas, contradicciones, acuerdos y consensos, en México el poder real es ejercido por una fracción (coalición) hegemónica dominante, quien es la que marca predominantemente el rumbo $y$ el destino del país, sobre todo en lo económico. Sin que ello implique estar exento de presiones de los grupos subalternos y un "poder" asumido parcialmente (formal) por las clases dominadas.
Bajo esta perspectiva, el poder aparentemente se comparte o está fragmentado y difuso, $y$ nadie puede poseer una cantidad excesiva del mismo. Existen intereses que compiten entre sí, $y$ dicha competencia es garantizada $y$ sancionada por el propio Estado, el cual garantiza la difusión $y$ el equilibrio del poder $y$ ningún interés particular pesa demasiado sobre él.

Consideramos que esta visión está equivocada en lo esencial. Efectivamente el Estado es una condensación material de fuerzas y luchas entre los dominantes y los dominados, pero ello no significa que el poder se diluya o se comparta. Pese a las conquistas de la clase trabajadora, el sistema de dominación y poder político, ideológico, y sobre todo económico, se mantienen inalterables en su esencia. En México, incluso, las conquistas históricas populares han tenido un serio retroceso en los años de aplicación de las políticas de ajuste estructural.

Es en el terreno de la economía donde más se vislumbra el poder y la dominación, pues en nada se ha modificado el régimen de propiedad y de control sobre los medios de producción; muy por el contrario, ahora se deposita toda la confianza en la iniciativa privada bajo un fanatismo ortodoxo.

En lo político, la libertad de expresión y los avances democráticos tan comentados por el ejecutivo, son en realidad mistificaciones que esconden, ocultan el verdadero carácter de clase del Estado mexicano.

Acabamos de vivir un proceso electoral, que aunque se niegue, estuvo plagado de irregularidades e incongruencias, donde la limpieza y la imparcialidad de este, quedan en duda. Todo ello orquestado ante los ojos de un IFE que permitió campañas sucias, intromisión de la cúpula empresarial y de la jerarquía eclesiástica y un Tribunal Electoral que estableció un triunfo a todas luces ilegítimo, que pone en la sala de terapia intensiva a nuestra incipiente democracia.

Todo ello cobijado en un poder mediático que cultivó el odio y el rencor, y que ahora llama a la unidad $y$ concordia de los mexicanos $y$ al respeto irrestricto de las instituciones. Fue este cinismo de la derecha la que orquestó el miedo al voto de la izquierda, y se apoderó del "imaginario colectivo" o "sentido común" de muchos mexicanos, $y$ terminamos pasando del fraude descarado 
del PRI a un "triunfo" que deja más dudas que certezas, y que la historia juzgará.

La negatividad de no volver a contar los $\operatorname{votos}^{18}$ bajo el "poderoso argumento" de que ya se habían contado; la declaración del TEPJF de que el "Presidente puso en riesgo la elección pero no fue determinante", de que los "empresarios apoyaron económicamente la campaña del miedo, pero no se puede determinar su impacto en la sociedad", pareciera una burla para el pueblo mexicano y abona caldo de cultivo para las luchas del contrapoder y contra institucionales, al margen de lo establecido por el estado y la clase política gobernante, en las que posiblemente el subcomandante Marcos (o Delegado Zero), con los brazos abiertos diga a todo el movimiento de resistencia civil pacífica y a la Convención Democrática Nacional, "Bienvenidos a la realidad".

\section{BIBLIOGRAFÍA}

Esteinou Madrid, Javier. "Medios de comunicación y transformación de la familia". En: Lozano, Juan Carlos y Benassini, Claudia (Editores). Anuario de investigación de la comunicación $I V$, Consejo Nacional para la Enseñanza de la Investigación de las Ciencias de la Comunicación (Coneicc)Departamento de Estudios de la Ciencias de la Comunicación (DESC). Jalisco. Universidad de Guadalajara, 1997.

Ibarra, David. El nuevo orden internacional. México. Nuevo Siglo y Aguilar, 1999.

Margáin, Eduardo. El TLC y la crisis del neoliberalismo mexicano. Los intereses, el poder y la distribución del ingreso en relaciones altamente asimétricas. México. Universidad Nacional Autónoma de México-Centro de Investigaciones sobre América del Norte, 1995.

18 La demanda del escrutinio de voto por voto no fue el capricho de un hombre, sino una demanda de millones de mexicanos.
Martinelli, José María (Coordinador). Políticas públicas en el nuevo sexenio. México. Universidad Autónoma MetropolitanaIztapalapa/Plaza y Valdés, 2002.

Medina Viedas, Jorge. Elites y democracia en México. México. Cal y Arena, 1998.

Meyer, Lorenzo. Fin de régimen y democracia incipiente, México hacia el siglo XXI. México. Editorial Océano, 1998.

Miliband, Ralph. El estado en la sociedad capitalista. México. Siglo XXI Editores, 1970.

Osorio, Jaime. Despolitización de la ciudadanía y gobernabilidad. México. Universidad Autónoma Metropolitana-Xochimilco, 1997.

Piñón, Ma. Auxilio y Rea Becerra, Rutilo Tomás. "Nueva hegemonía y bloque en el poder en México: de cara a las elecciones del año 2000". En: Revista de Ciencias Sociales, Universidad de Costa Rica, nro. 88, 2000, pp. 19-28.

Poulantzas, Nicos. Estado, poder y socialismo. México. Siglo XXI Editores, 1979.

Saldívar, Américo. Ideología y política del estado mexicano (1970-1976). México. Siglo XXI Editores, 1979.

Torre, Juan Carlos. El proceso político de las reformas económicas en América Latina. Buenos Aires. Paidós, 1998.

Uvalle Berrones, Ricardo. "La importancia de lo público en la vida del estado" en la Revista de Ciencias Sociales y Humanidades de la Universidad Autónoma MetropolitanaIztapalapa. México, 1999, nro. 46, juliodiciembre.

\section{PUBLICACIONES}

La Jornada-Internet, varios números 2006.

Proceso, varios números 2006. 